\title{
American Cutaneous Leishmaniasis in Panama: a historical review of entomological studies on anthropophilic Lutzomyia sand fly species
}

\author{
Larissa C Dutari ${ }^{1,2}$ and Jose R Loaiza ${ }^{1,3^{*}}$
}

\begin{abstract}
We review existing information on the epidemiology of American Cutaneous Leishmaniasis (ACL) in Panama, with emphasis on the bionomics of anthropophilic Lutzomyia sand fly species. Evidence from Panamanian studies suggests that there are six anthropophilic species in the country: Lutzomyia trapidoi, Lu. panamensis, Lu. gomezi, Lu. ylephiletor, Lu. sanguinaria and Lu. pessoana (Henceforth Lu. carrerai thula). In general, these taxa are abundant, widespread and feed opportunistically on their hosts, which make them potential transmitters of pathogens to a broad range of wildlife, domesticated animals and humans. Furthermore, nearly all man-biting species in Panama (with the exception of Lu. gomezi) expand demographically during the rainy season when transmission is likely higher due to elevated Leishmania infection rates in vector populations. Despite this, data on the distribution and prevalence of $A C L$ suggest little influence of vector density on transmission intensity. Apart from Lu. trapidoi, anthropophilic species seem to be most active in the understory, but vertical stratification, as well as their opportunistic feeding behavior, could vary geographically. This in turn seems related to variation in host species composition and relative abundance across sites that have experienced different degrees of human alteration (e.g., deforestation) in leishmaniasis endemic regions of Panama.
\end{abstract}

Keywords: Leishmania, Lutzomyia, Anthropophilic, Taxonomy, Bionomics, Vector control, Panama

\section{Background}

American Cutaneous Leishmaniasis (ACL) is a Neotropical infection caused by unicellular parasites in the genus Leishmania (Kinetoplastida: Trypanosomatidae) and transmitted by insect vectors in the genus Lutzomyia (Psychodidae: Phlebotominae) [1-3]. This disease persists endemically in forested areas of Panama where it represents a major health problem for children, who suffer severe skin lesions and face disfigurement following infection [4]. In addition, customs such as hunting and farming put middle-aged men at greater risk of transmission in non-endemic unstable settlements $[5,6]$. Epidemic cycles begin when a group of immunologically

\footnotetext{
*Correspondence: jloaiza@indicasat.org.pa

${ }^{1}$ Centro de Biodiversidad \& Descubrimiento de Drogas, Instituto de Investigaciones Científicas \& Servicios de Alta Tecnología, Edificio 219, Clayton, PO 0843-01103, Ciudad del Saber, República de Panamá

${ }^{3}$ Programa Centroamericano de Maestría en Entomología, Vicerrectoría de Investigación \& Postgrado, Universidad de Panamá, Ciudad de Panamá, República de Panamá

Full list of author information is available at the end of the article
}

naïve people such as military personnel, school teachers, scientists or international tourists enter sylvatic foci [6-15] [Figure 1].

Entomological research on ACL in Panama dates to the beginning of the $20^{\text {th }}$ century when the first occurrence records of sand flies (then known as Phlebotomus) were made in the country [16]. Graham Bell Fairchild and Marshall Hertig studied the natural history and systematics of sand fly species, describing several new taxa from various locales across Panama between 1941 and 1960. Led by Johnson T. Phyllis, Robert B. Tesh, Howard A. Christensen, Byron N. Chaniotis and Aristides Herrer research peaked in the next two decades, but shifted towards other areas such as Leishmania infections in the vectors, population dynamics, and interactions among parasites, vectors and hosts. These scientists and others put a great deal of effort into experimental and field work to disentangle the bionomics (i.e., the ecology and behavior) of Lutzomyia vector species and to identify the epidemiological determinants of the transmission cycle 


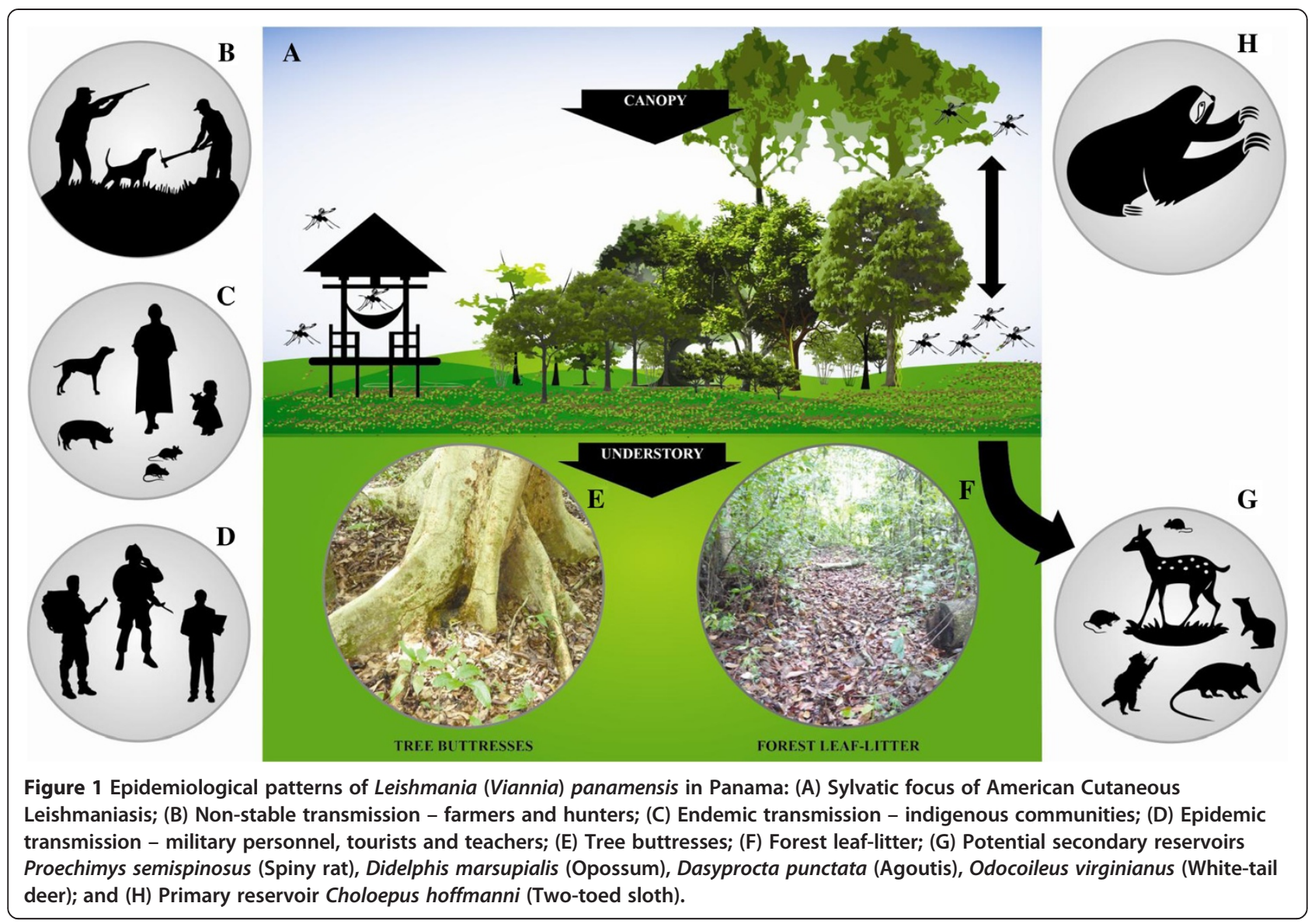

of ACL. During the next 30 years, research on ACL continued to focus generally on the same subjects but the rate of publication decreased gradually [Figure 2].

Collectively, the massive intellectual effort on ACL in Panama spanned roughly a century and resulted in approximately 100 peer-reviewed publications in international journals (Additional file 1: Table S1). These efforts stand as one of the greatest scientific contributions to the understanding of ACL epidemiology in Latin America. Recently, however, Panama has undergone significant changes in land use and human demography, and the epidemiology of ACL is thought to have changed considerably [14,17-24]. Surprisingly, few attempts have been made to summarize existing information about ACL in the country, despite its importance for predicting and controlling future epidemics [25]. In a review paper by Christensen et al., [11], which dates back to 1983, the authors synthesized information on the ecology of ACL, sand flies, animal reservoirs and the available clinical data from endemic areas of Panama. However, their review included all Lutzomyia sand fly species, rather than focusing on the anthropophilics. If effective vector control measures are to be implemented in Panama, information about the ecology and behavior of epidemiologically important Lutzomyia species needs to be synthesized [23-25]. Herein, we summarize the body of literature concerning the epidemiology of ACL and the bionomics of Lutzomyia sand flies in Panama, including information that was published after Christensen et al., [11], putting

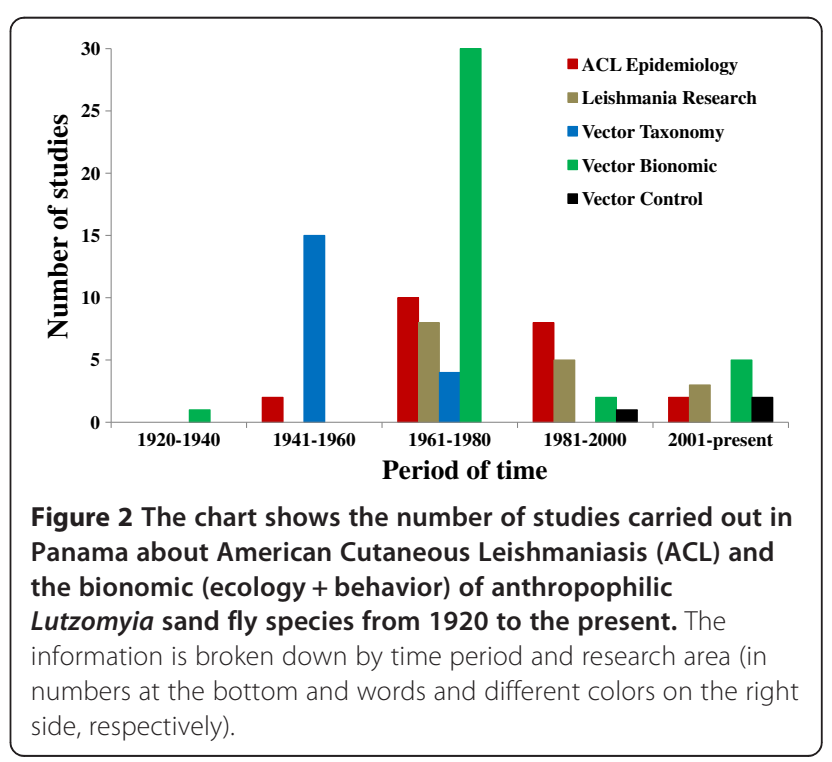


special emphasis on the most common anthropophilic species. This information will improve our understanding of potential changes in the transmission dynamics of this infection and contribute to the development of control strategies to limit Leishmania expansion across the country.

\section{Review \\ Epidemiology}

Historically, cases of ACL in Panama have fluctuated erratically, perhaps reflecting epidemic periods. However, these fluctuations may also be due in part to considerable underreporting because this disease has never been systematically monitored across the country [26]. Recently, some researchers have suggested a rising trend in the number of ACL cases in Panama, and attributed this to a lack of medical treatment, increased human migration into Leishmaniasis endemic areas, and/or to ecological changes triggering vector adaptation to human settlements in environmentally altered forest ecosystems [14,17-24]. Prior work in Panama though had also described a tendency toward increasing incidence of ACL, perhaps due to reasons different than those recently anticipated [4-9,11,12]. The scenario proposed earlier begins with a rapid increase in the number of clinical cases when susceptible human populations invade pristine tropical forest and modify the surroundings for settlements, thus increasing contact with the vectors and reservoirs of Leishmania parasites [Figure 1]. However, subsequent landscape alteration triggers demographic changes in wild animals, occasionally resulting in major reservoirs of Leishmania migrating out of the territory, and as a result, ACL cases drop off considerably. Finally, the disease disappears when sand fly vectors perish due to the lack of appropriate breeding conditions in the increasingly urban landscape $[4-9,11,12]$. This view is well-accepted as Panama has always been under similar environmental pressures (e.g., deforestation), and therefore, the recently-reported ACL increase is most likely an artifact of enhanced surveillance due to improved diagnostic tools and better access to health care [18,22,27] [Figure 3]. Alternatively, the increasing trend in the number of ACL cases could be the result of greater human-vector contact owing to higher rates of deforestation and human population growth across areas of oldgrowth forest in Panama during the last 30 years [28].

\section{Leishmania transmission cycles}

Many more studies have been undertaken on the vectors of ACL in Panama than on Leishmania parasites [Figure 2]. To date, seven Leishmania species have been reported in the country, but only three have been isolated from humans: Leishmania (Viannia) panamensis, Le. (Viannia) colombiensis and Le. (Leishmania) amozanensis, with the

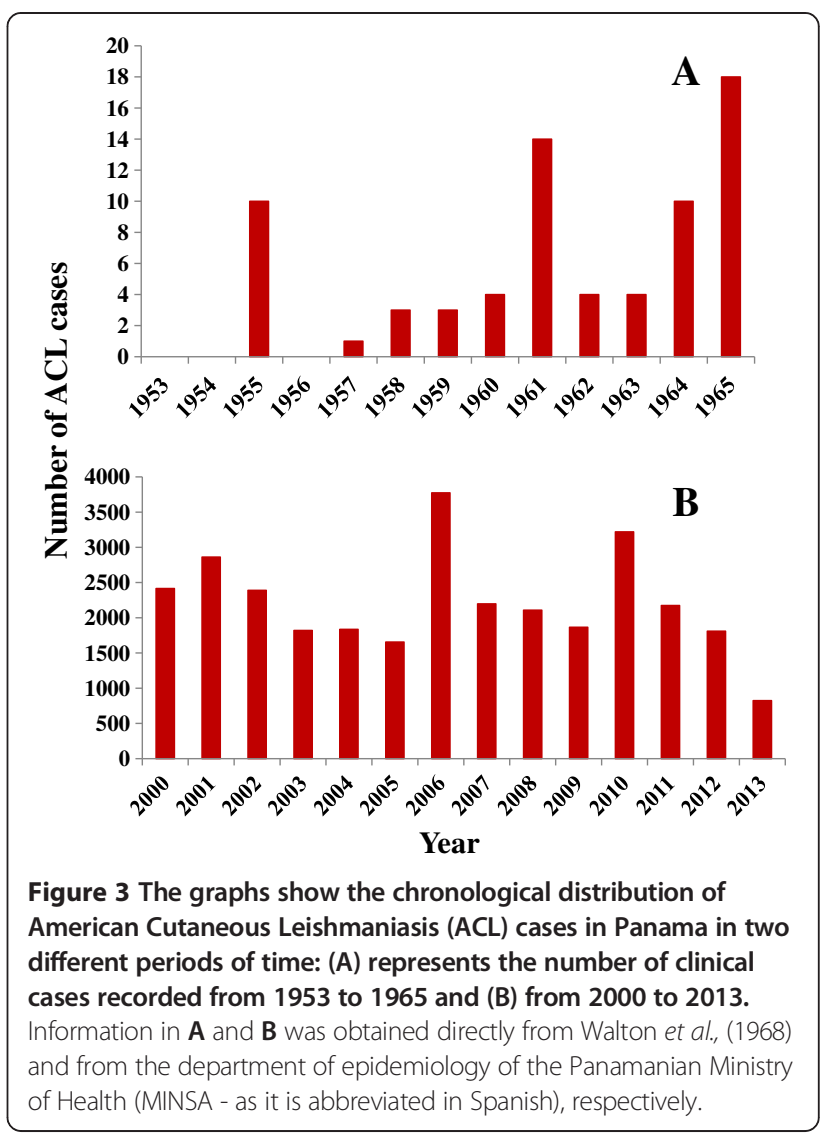

former being by far the most predominant disease agent [2,6,10-12,18,29-33]. Furthermore, three other species Le. (Leishmania) aristidesi, Le. (Leishmania) hertigi and Le. (Viannia) naiffi have been detected either from animal hosts (e.g., Le. $(L)$ aristidesi was isolated from Oryzomys capito, Agouti paca, Marmosa robinsoni and Proechimys semispinosus and Le. (L) hertigi from Coendou rothschildi) or from wild-caught Lutzomyia sand flies (e.g., Le. (V) naiffi was isolated from pools of Lu. trapidoi and $L u$. gomezi), of which only the latter is pathogenic to humans [1,11,34-36].

The enzootic cycles of Le. (V) panamensis and Le. $(L)$ aristidesi are best known in Panama, but ecological knowledge about the transmission dynamics of other species remains incomplete [29,34,37-40]. These two parasites appear to utilize different sand fly vectors and vertebrate reservoirs, and their transmission dynamics seem to be governed by a different set of epidemiological factors. Leishmania (Viannia) panamensis is certainly transmitted by several species of Lutzomyia sand flies across the country, whereas Le. $(L)$ aristidesi appears limited to eastern Panama, where it seems to be transmitted by a single sand fly species. Lutzomyia trapidoi and Lu. panamensis, the proven vectors of Le. $(V)$ panamensis in Panama and Colombia as well as other 
suspected vectors such as $L u$. gomezi, Lu. ylephiletor, $L u$. sanguinaria and $L u$. carrerai thula are very abundant and highly aggressive anthropophilic species. They feed opportunistically, primarily in the understory, but can do so in the forest canopy as well $[12,41,42]$. In contrast, Lutzomyia olmeca bicolor, the likely vector of Le. $(L)$ aristidesi, is considered a rare subspecies that feeds almost exclusively on rodents and is most active at ground level $[37,43]$. Despite several animal species being found infected in nature with $L e$. ( $V$ ) panamensis and $L e .(L)$ aristidesi, studies aimed at identifying the reservoirs of these two parasites have indicated that they are largely restricted to one arboreal and one terrestrial mammal species, respectively [29,37,38,44-47]. This may explain why transmission intensity does not appear to be a function of vector density, but rather seems to be related to the density of the animal reservoirs $[45,47]$. For example, high transmission rates of Le. ( $V$ ) panamensis may occur in areas of old-growth forest with high population densities of the two-toe sloth, Choloepus hoffmanni. Similarly, elevated densities of the rice-rat, Oryzomys capito, in areas of secondary forest and agricultural land seem to favor high transmission rates of Le. $(L)$ aristidesi $[37,38,44,48]$. Other animals, including Didelphis marsupialis (Opossum) and Proechimys semispinosus (Spiny rat), may serve as secondary reservoirs for these parasites in Panama, but their epidemiological roles have not been fully investigated $[44,46]$. A likely reason why ACL transmission does not occur on domestic environments in endemic areas of Panama is that dogs and humans appear to be dead end-hosts for Le. (V) panamensis $[4,11,44,49]$.

\section{Summary of research on vector taxonomy}

Research on sand fly taxonomy represents less than $20 \%$ of the ACL studies undertaken in Panama, yet these efforts are essential for understanding the role of Lutzomyia species as vectors of this infection [Figure 2]. Raymond C. Shannon described the first species of sand fly from the country in 1926, at which time there were only nine species formally described from South America. Phlebotomus panamensis was first collected by Shannon with a sweeping net near the roots of a Cuipo tree in Cano Saddle, Gatun Lake and later again in Portobelo on the Atlantic side of the Isthmus. By 1961, Fairchild and Hertig had described more than 20 species of sand flies from numerous locales across Panama, although most originated from the Former Panama Canal Zone [50-64]. These taxonomic descriptions included specimens from other non blood-sucking genera of Psychodidae (e.g., Warileya and Hertigia), but most of them dealt with the adult stage of members of the genus Phlebotomus $($ Herein $=$ Lutzomyia $)$ [65] (Additional file 2: Table S2).
Three taxonomic papers written by Fairchild and Hertig were of particular importance for understanding the transmission cycle of ACL in Panama: the morphological separation of $L u$. gomezi and $L u$. trinidadensis [52]; the description of Lu. trapidoi and Lu. ylephiletor (also known as Lu. ylepiletrix) [55]; and the re-description of Lu. panamensis [56]. The first two taxa are morphologically similar, very abundant species that often co-occur geographically, but only $L u$. gomezi is considered an important vector of ACL in Panama because it feeds regularly on humans. Moreover, Lu. trapidoi, Lu. ylephiletor and $L u$. panamensis are among the most prevalent man-biters as well as proven ACL vectors in Panama and in other Neotropical countries [2,6,18,33,41,42,66-68]. Additional systematic work on sand flies from Panama described two new taxa one of which was Lu. olmeca bicolor, and added new records for other species described elsewhere, for a total of 74 morphologically characterized taxa for the country $[69,70]$.

\section{Taxonomic markers}

Fairchild and Hertig published several morphological keys of Lutzomyia species from Panama, including epidemiologically relevant Leishmania vectors, as well as numerous other species from other parts of Central America [50,55-61,63,71]. This initial taxonomic work emphasized the female cibarium and the male genitalia as the most valuable morphological characters for distinguishing species. These structures contain a suit of characters that make species discrimination in both sexes accurate and feasible in a short period of time [63]. In contrast, morphometric analyses using venational characters (e.g., overall wing and vein lengths) and/or the palpal formula (e.g., listing the palpus segments in order of increasing length) have been shown to have little systematic value because these characters vary considerably among members of well-recognized morphological species and also among individuals of the same taxon $[51,52,54,55,57,58,63,70,72]$.

Taxonomic studies of the immature stages of sand flies began formally in Panama with the doctoral dissertation of Wilford J. Hanson in 1955, which was later published in the Annals of the Entomological Society of America [73]. Contrary to the approach used in adult taxonomy, which focused on internal structures, identification of the immature stages depended more on the Chaetotaxy (e.g., the distribution of setae in the insect body). Setae at the head capsule, thorax and abdomen vary in number, position, length and shape and are very important for species determination. These sensorial structures are thought to be serially homologous between adjacent segments, and so are comparable among the prothrorax, mesothorax and metathorax [73,74]. More recent taxonomic work using molecular markers supports the validity 
of 16 species of sand flies from central Panama including Lu. trapidoi, Lu. panamensis, Lu. ylephiletor, Lu. carrerai thula and Lu. sanguinaria, but suggests lineage divergence in Lu. gomezi [33]. The authors of this study hypothesized that $L u$. gomezi is a cryptic species complex based on phylogenetic analyses using partial DNA sequences from the Folmer or "Barcode" region of the mitochondrial CO1 gene. This finding is of particular epidemiological significance because morphologically identified $L u$. gomezi was found infected with Le. (V) naiffi, at an infection rate of $23 \%$. This pathogen causes cutaneous Leishmaniasis in South America and had never been reported in Panama previously [33]. Although there seems to be a high level of congruence between morphology and DNA Barcoding based taxonomy for Lutzomyia species in Panama, there is still a need to corroborate species boundaries using samples from across the entire country [75].

\section{Summary of studies on the bionomics of anthropophilic Lutzomyia species Larval breeding habitats}

Research on sand fly larval ecology in Panama has tackled aspects such as species habitat associations and environmental factors affecting population dynamics $[11,45,63,73,74,76-79]$. These studies relied on either direct observations or sampling techniques and resulted in a series of valuable publications that increased understanding of the biology and ecology of these insects. Hanson [73] collected fourth instar larvae of Lu. trapidoi, Lu. panamensis, Lu. ylephiletor and Lu. carrerai thula in dead (decaying) leaves from the forest floor of well-shaded areas [Figure 1]. His research demonstrated that larvae of these species tend to gather on moist, decaying areas on the upper and lower surfaces of leaves [73,74]. Furthermore, both females and males of Lu. trapidoi, $L u$. panamensis, Lu. ylephiletor and Lu. carrerai thula were encountered resting in the same habitat during the day, suggesting that forest leaf-litter may not only serve as emergence and resting sites, but also as ovipositon and mating grounds for these taxa [11].

Studies by Rutledge and Ellenwood [49] used soil emergence traps in the forest floor of Gamboa, central Panama, to test for larval-habitat associations in sand flies. Lutzomyia trapidoi was most abundant on open forest floor, whereas $L u$. panamensis, $L u$. gomezi and $L u$. carrerai thula were collected regularly, but in significantly lower numbers. Furthermore, the micro-spatial distribution of anthropophilic species appeared to vary with plant species composition, which ultimately seems to determine the size of the population in a given area. For example, larvae of Lu. panamensis and Lu. gomezi tended to be more abundant in association with large trees of the genus Anacardium (Anacardiaceae) while larvae of $L u$. trapido $i$ were usually more prevalent in association with large lianas in the genera Ourouparia and Sabicea (Rubiaceae) [77]. Additionally, hydrological and physiographic factors such as soil moisture, erosion, percentage of shade and the depth of the forest leaf-litter affect soil movement and stability, and thus can also influence species distribution in the forest floor. For instance, larvae of Lu. panamensis and Lu. gomezi were more abundant in hilltops where forest leaf-litter was more stable, whereas Lu. trapidoi colonized hillside and streamside regions where unstable alluvial deposits were more common [76].

\section{Adult resting sites and vertical stratification}

Diurnal resting sites for anthropophilic Lutzomyia species in forest environments of Panama were described by Christensen et al., [6,11], Christensen and Vasquez [68], and Chaniotis et al., [80-82]. On the whole, this work indicated that tree hollows and animal burrows were the most productive resting habitats in terms of species richness, but suggested that tree buttresses and forest leaflitter were more important from the epidemiological stand point [Figure 1]. This is because the latter were the most conspicuous resting habitats in the forest, and were also preferred by anthropophilic species. These studies also indicated that Lu. trapidoi, Lu. panamensis and $L u$. gomezi were more abundant in forest leaf-litter, whereas Lu. ylephiletor and Lu. carrerai thula were more prevalent in tree trunks and in green plants, respectively $[11,81]$. Moreover, Lu. ylephiletor dominated tree buttresses at six different ACL sylvatic foci across the country, where it represented roughly $43 \%$ of the total sample of resting sand flies [12,68].

Studies of vertical stratification of sand flies in Panama were conducted in forest environments using both resting and blood-seeking samples as well as various collecting methods (e.g., human and animal baits, light traps and resting collections) $[11,40,49,68,80-83]$. In general, the results suggested that there is some degree of vertical partitioning of the niche because females of most species tend to cluster at the ground level, but few of them are active in the canopy. These behaviors are more obvious in $L u$. panamensis, Lu. gomezi, Lu. ylephiletor and Lu. carrerai thula, whose populations are usually more numerous a few meters off the ground. In contrast, Lu. trapidoi and Lu. sanguinaria are more abundant at higher elevations (but see also [41]). Lutzomyia trapidoi might be the only proven acrodendrophilic species in the country, because it has been found 18 meters above the ground, both resting and blood-seeking, whereas Lu. sanguinaria has only been collected in light traps at this elevation $[11,84]$. Nevertheless, the extent of vertical stratification also varied geographically. For example, Lu. panamensis is considered a ground-level feeder in central Panama, but it was the most abundant species in the canopy in one study carried out in eastern Panama [49]. Similarly, Lu. gomezi 
and Lu. sanguinaria have been collected in great numbers in the forest canopy in Bocas Del Toro, despite being considered understory species in most studies carried out in central Panama [11,41]. Moreover, in some circumstances Lu. trapidoi has been the most abundant species at the understory regardless of which collecting method was employed. Therefore, rather than clustering at different vertical strata, anthropophilic sand fly species may move freely between the canopy and the understory seeking their preferred vertebrate hosts; and while doing so, they may also take blood from alternative hosts depending on their relative abundance [Figure 1]. This might explain why Lu. trapidoi, Lu. panamensis, Lu. gomezi and Lu. sanguinaria exhibit different host-feeding preferences at different vertical strata in different sites (See next section).

\section{Biting activity and vector-host interactions}

Chaniotis et al., [80] investigated the daily biting activity of anthropophilic Lutzomyia species in central Panama. In agreement with similar studies from other regions of the country, they found that roughly $80 \%$ of the female biting takes place during crepuscular periods, mainly from 6:00 to 9:00 pm [11,49,66,67,85]. This pattern remained the same for most anthropophilic species, despite differences in density across vertical strata and climatic season, and seemed to be primarily associated with a reduction in light intensity [12]. However, Lu. carrerai thula, a dominant subspecies in the understory, was unaffected by light intensity and exhibited higher daytime biting rates, being more active at low temperature and high humidity $[11,12,68]$. Furthermore, studies on the horizontal movements of Lutzomyia have reported a major reduction in the biting rate of Lu. panamensis, Lu. trapidoi and Lu. carrerai thula in collections made 50 meters away from areas of old-growth tropical forest. Collectively these findings suggest that the highest risk of ACL transmission in endemic areas of Panama occurs early at night and inside the forest, but diurnal transmission might also occur where Lu. carrerai thula is prevalent. The role of this taxon as a vector of Le. $(V)$ panamensis in the country has not been confirmed though $[11,83]$.

Research on Lutzomyia host interactions began in Panama with the pioneering work of Tesh et al., [66,67], who employed the precipitin test and nine Order-specific mammalian antisera to provide the first assessment of Lutzomyia feeding preferences in the Americas. Their results suggested that some anthropophilic species are highly specific at the Order level and prefer to feed upon a single mammalian Order (e.g., 73\% of Lu. carrerai thula fed on Edentates and 100\% of Lu. sanguinaria fed on Primates). However, the two most abundant species, $L u$. trapidoi and Lu. ylephiletor, exhibited opportunistic feeding behavior, shifting host preferences across sites according to changes in the relative abundance of the mammalian fauna. Interestingly, $\mathrm{Lu}$. trapidoi and $\mathrm{Lu}$. ylephiletor shifted blood choices from Edentates to rodents and marsupials between undisturbed forest at El Limbo Field Station, in central Panama, and humanaltered forest ecosystems at Finca Montenegro and Finca el Valle, respectively. This was the first evidence in Panama that deforestation could alter the feeding preferences of Lutzomyia sand fly species by triggering host community changes and/or host species decline. Results from Tesh et al., [66,67] were in disagreement with those from Christensen and Vasquez [69], who studied Lutzomyia host-feeding sources across the country, including localities from western and central-eastern Panama. While both Lu. trapidoi and Lu. ylephiletor favored Edentates over other mammalian Orders in Tesh et al., [66,67], Christensen and Vasquez [69] reported that Lu. ylephiletor fed on more than 20 different families of mammals, birds, reptiles and even amphibians, whereas Lu. trapidoi fed almost exclusively on sloths (e.g., Choloepus hoffmanni). The discrepancies between studies may be attributed to a lower resolution in the study by Tesh et al., [66], which did not determine host taxonomic identity beyond the class level, and also due to potential sampling biases as numerous sentinel monkeys and rodents were set up in the study area [67]. Alternatively, the larger number of sampling sites included in the study by Christensen and Vasquez [68] may indicate that Lu. ylephiletor is more of a catholic feeder than $L u$. trapidoi.

Evidence from Panamanian studies suggests that there are six anthropophilic species of Lutzomyia in ACL endemic areas of Panama: Lu. trapidoi, Lu. panamensis, Lu. ylephiletor, Lu. gomezi, Lu. sanguinaria and Lu. carrerai thula $[12,44,66-68,80,81,86-89]$. In general, these species are opportunistic, which makes them potential transmitters of pathogens across a broad range of wildlife, domesticated animals and humans [84,90]. Nevertheless, as pointed out before, under certain circumstances some species can also be host-specific. For instance, $L u$. sanguinaria has been found to feed upon five different mammalian Orders in Sasardi Kuna Yala, eastern Panama, but exhibited a strong preference for dogs in central Panama [11,49]. These studies further support the view that Lutzomyia host trophic interactions (e.g., host-specific vs. opportunistic, and canopy vs. understory feeding) are ultimately determined by the richness and relative abundances of animal host species in forest environments of Panama, which in turn are affected by the degree of human alteration in these places (e.g., deforestation).

\section{Seasonal trends}

Evidence for sand fly seasonality in Panama comes from both larval and adult studies, but results from these 
investigations are not readily comparable due to differences in sampling approaches and ecological factors inherent to each developmental stage. Nevertheless, the two approaches have reached similar conclusions [11,49,87]. Chaniotis et al., [79,84] studied the seasonality of Phlebotominae sand flies at El Limbo Field Station, in central Panama. The results demonstrated that most anthropophilic species peak in density during the wet season, although populations of $\mathrm{Lu}$. panamensis and Lu. carrerai thula increased in the early wet season between June and August, whereas Lu. trapidoi, Lu. ylephiletor and Lu. sanguinaria increased in October and November during the late wet season (but see also $[47,87,88]$ ). Furthermore, wet-adapted species decreased significantly during the dry season; disappearing almost entirely from the study area, while $L u$. gomezi, a dry-adapted species, was more abundant at this time of the year. Studies by Chaniotis et al., $[80,86]$ also indicated that overall sand fly seasonal trends (which included the anthopophilic species) did not vary according to biotope (old-growth forest vs. secondary growth forest), vertical strata (canopy vs. understory) or sex (female vs. male). Abundances were mostly influenced by the amount and distributional pattern of rainfall, as there was little variation in monthly mean temperature and relative humidity [86]. Similarly, studies on the patterns of adult emergence in the forest soils of central Panama have confirmed that anthropophilic sand fly species are highly seasonal, with cyclical trends most evident in Lu. trapidoi and Lu. gomezi. Newly emerged populations of these two species peaked in density in different periods of the year: the former being more abundant during the rainy season, from May to September, and the latter increasing in numbers from January to April [45]. Overall, these seasonal patterns may be associated with higher transmission rates of ACL during the rainy season in Panama, likely due to increased Leishmania infection rates in vector populations around this time of the year. However, as pointed out earlier, the distribution and prevalence of ACL in Panama suggests that vector density has little influence on transmission intensity, which could be even higher in sites where zoophilic sand fly species dominate over anthropophilics [45,88].

\section{Vector control}

Studies on sand fly control are very limited in Panama and account for less than five scientific publications during the entire history of ACL research in this country $[12,23,24,91]$ [Figure 2]. This may be in part due to the nature of this non-fatal and chronic zoonotic disease, which affects people in remote rural areas rather than in urban centres [26]. It may also reflect the complicated and impractical task of controlling sand fly populations in forest environments [49]. Early studies of vector control in Panama evaluated three methods of personal protection [91]. Researchers found that skin applications with N,N-diethyl-meta-toluamide (DEET) conferred good protection against the bites of Lu. panamensis, Lu. gomezi and $L u$. sanguinaria. However, this protection lasted only for a few hours, whereas DEET-treated net jackets offered protection for up to two weeks. In contrast, permethrintreated clothing did not offer protection against Lutzomyia bites. It was concluded that full protection could only be achieved by combining the use of DEET-treated net jackets with DEET skin applications on those areas that are not covered by the jacket [91].

Insecticide control trials with 95\% technical grade malathion using Ultra Low Volume (ULV) and 2\% malathion Emulsifiable Concentrate (EC) in hand-operated sprayers were carried out by Chaniotis et al., [12] to attempt to control sand fly populations in a sylvatic focus of ACL on the Atlantic coast of central Panama. The authors applied insecticide around Lutzomyia resting sites to prevent ACL transmission to military personnel, and assessed the efficacy of this treatment by collecting blood-seeking and resting females near tree trunks after treatment. They found that sand fly density was reduced by $52.8 \%$ and $44.7 \%$ by ULV and EC applications, respectively, in comparison with the pretreatment period. However, differences were only statistically significant for the latter. More recent studies using insecticide thermal fogging in a hyperendemic focus of ACL in central Panama reported a decrease in the Lutzomyia species richness between deltamethrin-treated and untreated houses, although anthropophilic species were still present after treatment. The relative abundance of $L u$. gomezi and $L u$. panamensis was reduced by roughly $50 \%$ in deltamethrin-treated houses, but the population of $L u$. trapidoi increased by $5 \%$. The authors hypothesized that sand fly re-infestation was facilitated by poor housing quality, since unsuitable building materials would either provide additional resting sites for sand flies or hamper insecticide efficacy by reducing its active lifespan [23,24]. Together these findings reflect the short-lasting nature of these insecticide control measures, which do not affect the immature stages of sand flies in the forest. However, these observations do highlight the importance of evaluating the effectiveness of insect repellents and insecticide treatment, in order to successfully integrate strategies for Lutzomyia control in Panama. Results from these studies also emphasize the need for adopting a community based approach to better understand the role of anthropophilic Lutzomyia species on ACL transmission dynamics across the country $[23,24]$. Considerably more scientific work on vector control is required in Panama, including the need to follow up on studies about the presence of the bacterium Wolbachia pipientis in pools of Lu. trapidoi as a potential biocontrol strategy to mitigate Lutzomyia populations [33]. 


\section{Conclusion}

The last review paper published about ACL research in Panama was written 30 years ago [11]. Since then the country has undergone significant changes in landscape and human demography, and more people are commonly in contact today with forest environments where the sylvatic focus of ACL takes place. As a result, more clinical cases are being reported in local human populations as well as in international visitors. This increase in clinical cases could also be due to underreporting in the past or improved Leishmania diagnostic tools and better access to health care at present. Advanced research about ACL epidemiology and Lutzomyia bionomics is still needed in Panama. These efforts will be greatly strengthened by the integration of modern technologies such as bioinformatics, modeling, and genomic markers to investigate population genetics and molecular taxonomy of anthropophilic Lutzomyia species. In addition, more sophisticated analyses using geographic information systems (GIS) and ecological niche modeling (ENM) techniques on vector species will be required to predict ACL transmission risk across the country. Finally, future research about ACL in Panama will benefit from adopting a more holistic approach, where integrated vector control strategies are planned based on information generated from scientific research. We hope that our review will contribute to this goal as it provides a synopsis of taxonomic and bionomic information of epidemiologically relevant $L u t$ zomyia species in the country. This information, along with knowledge about the impact of human landscape modifications on ACL epidemiology, will help to predict and control future epidemics.

\section{Additional files}

Additional file 1: Table S1. Body of literature concerning the epidemiology of American Cutaneous Leishmaniasis (ACL) and the bionomics of Lutzomyia sand flies in Panama.

Additional file 2: Table S2. Record of taxonomic studies of Lutzomyia sand fly species from Panama.

\begin{abstract}
Abbreviations
ACL: American Cutaneous Leishmaniasis; DNA: Deoxyribonucleic acid; CO1: Cytochrome C oxidase one; DEET: N,N-diethyl-meta-toluamide; ULV: Ultra low volume; EC: Emulsifiable concentrate; GIS: Geographic information system; ENM: Ecological niche modeling.
\end{abstract}

\section{Competing interests}

The authors declare that they have no competing interests.

\section{Authors' contributions}

LCD and JRL wrote the review; both authors read and approved the final version of the manuscript.

\section{Acknowledgments}

We want to thank Donald M. Windsor and Diana Sharpe from the Smithsonian Tropical Research Institute (STRI), who critically commented on an earlier version of this work. Rita Marissa Giovani and Ronnie Gavilán from the Instituto de Investigaciones Científicas y Servicios de Alta Tecnología
(INDICASAT-AIP) helped to generate the sketch on Figure 1. William Lainhart from the Department of Biological Sciences at the University at Albany, New York (SUNY) helped to obtain the PDF files of several publications. The Secretariat for Science, Technology and Innovation of Panama (SENACYT) through a scholarship awarded to LCD and the National Research Investigator Board (SNI) prize granted to JRL financed this research.

\section{Author details}

${ }^{1}$ Centro de Biodiversidad \& Descubrimiento de Drogas, Instituto de Investigaciones Científicas \& Servicios de Alta Tecnología, Edificio 219, Clayton, PO 0843-01103, Ciudad del Saber, República de Panamá. 2Department of Biotechnology, Acharya Nagarjuna University, Guntur, India. ${ }^{3}$ Programa Centroamericano de Maestría en Entomología, Vicerrectoría de Investigación \& Postgrado, Universidad de Panamá, Ciudad de Panamá, República de Panamá.

Received: 21 February 2014 Accepted: 1 May 2014 Published: 11 May 2014

\section{References}

1. Reithinger R, Dujardin JC, Louzir H, Pirmez C, Alexander B, Brooker S: Cutaneous Leishmaniasis. Lancet Infect Dis 2007, 7(9):581-596.

2. Maroli M, Feliciangeli D, Bichaud L, Charrel R, Gradoni L: Phlebotomine sandflies and the spreading of Leishmaniases and other diseases of public health concern. Med Vet Entomol 2013, 27(2):123-47.

3. Ready PD: Biology of phlebotomine sand flies as vectors of disease agents. Annu Rev Entomol 2013, 58:227-50.

4. Herrer A, Christensen HA: Epidemiological patterns of Cutaneous Leishmaniasis in Panama III. Endemic persistence of the disease. Am J Trop Med Hyg 1976, 25(1):54-58.

5. Herrer A, Christensen HA, Beumer RJ: Epidemiological patterns of Cutaneous Leishmaniasis in Panama II. Incidental occurrence of cases in no-endemic settlements. Ann Trop Med Parasitol 1976, 70(1):67-71.

6. Christensen HA, De Vasquez AM, Petersen JL: Short report: epidemiologic studies on Cutaneous Leishmaniasis in eastern Panama. Am J Trop Med Hyg 1999, 60:54-57.

7. Kean BH: Cutaneous Leishmaniasis on the Isthmus of Panama. Arch Dermatol Syph 1944, 50(4):237-238.

8. Snow JS, Satulsky EM, Kean BH: American Cutaneous Leishmaniasis: report of 12 cases from the Canal Zone. Arch Dermatol Syph 1948, 7(1):90-101.

9. Herrer A, Christensen HA: Epidemiological patterns of Cutaneous Leishmaniasis in Panama I. Epidemics among small groups of settlers. Ann Trop Med Parasitol 1976, 70(1):59-65.

10. Takafuji ET, Hendriks LD, Daubek JL, McNeil KM, Scagliola HM, Diggs CL: Cutaneous Leishmaniasis associated with jungle training. Am J Trop Med Hyg 1980, 29(4):516-520.

11. Christensen HA, Fairchild GB, Herrer A, Johnson CM, Young DG, De Vasquez AM: The ecology of Cutaneous Leishmaniasis in the Republic of Panama. J Med Entomol 1983, 20:463-484.

12. Chaniotis BN, Parsons RE, Harlan HJ, Correa MA: A pilot study to control Phlebotomine sand flies (Diptera: Psychodidae) in a Neotropical rain forest. J Med Entomol 1982, 19(1):1-5.

13. Chaniotis BN, Johnson CM, Christensen HA, De Vasquez AM: Acquisition, development, and treatment of Panamanian Cutaneous Leishmaniasis: a case history. Mil Med 1988, 153(8):405-6.

14. Crum NF, Aronson NE, Lederman ER, Rusnak JM, Cross JH: History of US military contributions to the study of parasitic diseases. Mil Med 2005, 170(4):17-29.

15. Walton BC, Person DA, Bernstein R: Leishmaniasis in the U.S. military Canal Zone. Am J Trop Med Hyg 1968, 17(1):19-24.

16. Shannon RC: The occurrence of Phlebotomus in Panama. J Wash Acad Sci 1926, 16(7):190-193.

17. Zeledón R: Leishmaniasis in the Caribbean islands: a review. Ann NY Acad Sci 1992, 653:154-160.

18. Miranda A, Carrasco R, Paz H, Pascale JM, Samudio F, Saldaña A, Santamaría G, Mendoza Y, Calzada JE: Molecular epidemiology of American Tegumentary Leishmaniasis in Panama. Am J Trop Med Hyg 2009, 81:565-571.

19. Valderrama A, Herrera M, Salazar A: Relación entre la composición de especies del género de Lutzomyia frança (Diptera: Psychodidae: 
Phlebotominae) y los diferentes tipos de bosques en Panamá. Acta Zool Mex 2008, 24(2):67-78.

20. Valderrama A, Tavares García M, Andrade Filho JD: Anthropogenic influence on the distribution, abundance and diversity of sand fly species (Diptera: Psychodidae: Phlebotominae), vectors of Cutaneous Leishmaniasis in Panama. Mem Inst Oswaldo Cruz 2011, 106(8):1024-1031.

21. Restrepo CM, Pérez Lao E, De la Guardia C, Sousa OE, Calzada JE, Lleonart R: Amplified fragment length polymorphism reveals high intraspecific variability in field isolates of Leishmania panamensis. Curr Trends Biotechnol Pharm 2011, 5:1183-1192.

22. Saldaña A, Chaves LF, Rigg CA, Wald C, Smucker JE, Calzada JE: Clinical Cutaneous Leishmaniasis rates are associated with household Lutzomyia gomezi, Lu. panamensis and Lu. trapidoi abundance in Trinidad de Las Minas, western Panama. Am J Trop Med Hyg 2013, 88(3):572-574.

23. Calzada JE, Saldaña A, Rigg C, Valderrama A, Romero L, Chaves LF: Changes in Phlebotomine sand fly species composition following insecticide thermal fogging in a rural setting of western Panama. PLoS ONE 2013, 8(1):e53289.

24. Chaves LF, Calzada JE, Rigg C, Valderrama A, Gottedenker N, Saldaña A: Leishmaniasis sand fly vector density reduction is less marked in destitute housing after insecticide thermal fogging. Parasit Vectors 2013, 6:164.

25. Stockdale L, Newton R: A review of preventive methods against human Leishmaniasis infection. Plos Negl Trop Dis 2013, 7(6):e2278

26. Alvar J, Vélez ID, Bern C, Herrero M, Desjeux P, Cano J, Jannin J, Den Boer M: Leishmaniasis worldwide and global estimates of its incidence. PLOS ONE 2012, 7(5):e35671.

27. Miranda A, Saldaña A, González K, Paz H, Santamaría G, Samudio F, Calzada $J E$ : Evaluation of PCR for Cutaneous Leishmaniasis diagnosis and species identification using filter paper samples in Panama, Central America. Trans R Soc Trop Med Hyg 2012, 106(9):544-548.

28. Wright SJ, Samaniego MJ: Historical, demographic and economic correlates of land-use change in the Republic of Panama. Ecol Soc 2008, 13(2):17.

29. Christensen HA, Herrer A: Detection of Leishmania brazilienzis by xenodiagnosis. Trans R Soc Trop Med Hyg 1972, 66(5):798-799.

30. Vásquez A, Paz H, Alvar J, Pérez D, Hernández C, Informe final: Estudios sobre la epidemiología de la Leishmaniasis en la parte occidental de la República de Panamá. Ministerio de Salud: Instituto Conmemorativo Gorgas de Estudios de la Salud; 1990.

31. Petersen J, Johnson CM, De Vásquez AM, Sáenz RE: Cutaneous Leishmaniasis caused by Leishmania mexicana amazonensis in Panama. Rev Med Panama 1988, 13(1):158-164.

32. Kreutzer RD, Corredor A, Grimaldi G, Grogl M, Rowton ED, Young DG, Morales A, McMahon-Pratt, Guzman H, Tesh RB: Characterization of Leishmania colombiensis sp. (Kinetoplastida: Trypanosomatidae), a new parasite infecting humans, animals, and Phlebotomine sand flies in Colombia and Panama. Am J Trop Med Hyg 1991, 44(6):662-675.

33. Herrer A, Telford SR: Leishmania braziliensis isolated from sloths in Panama. Science 1969, 164(3886):1419-1420.

34. Herrer A: Leishmania hertigi sp. N. from the tropical porcupine, Coendou rothschildi Thomas. J Parasitol 1971, 57(3):626-629.

35. Herrer A, Christensen HA, Telford SR Jr: Enzootic Cutaneous Leishmaniasis in Eastern Panama I. Investigation of the infection among forest mammals. Ann Trop Med Parasitol 1971, 65:349-358.

36. Azpurua J, De la Cruz D, Valderrama A, Windsor D: Lutzomyia sandfly diversity and rates of infection by Wolbachia and an exotic Leishmania species in Barro Colorado Island, Panama. PLoS Negl Trop Dis 2010, 4(3):e627.

37. Herrer A, Christensen HA, Beumer RJ: Reservoir host of Cutaneous Leishmaniasis among Panamanian forest mammals. Am J Trop Med Hyg 1973, 22:585-591.

38. Christensen HA, Herrer A: Development of a Panamanian strain of Leishmania mexicana in co-indigenous Lutzomyia sanguinaria and $L u$. gomezi (Diptera: Psychodidae). J Med Entomol 1980, 17:188-189.

39. Herrer A, Christensen HA: Leishmania braziliensis in the Panamanian two-toed sloth, Choloepus hoffmani. Am J Trop Med Hyg 1980, 29(6):1196-200.

40. Saénz RE, Paz HM, De Rodríguez GC, De Vásquez AM, Mata RE: Mucocutaneous Leishmaniasis in Panama: etiologic agent, epidemiologic and clinical aspects. Rev Med Panama 1989, 14:6-15.

41. Johnson P, McConmell E, Hertig M: Natural infection of Leptomoned flagellates in Panamanian Phlebotomus sandflies. Experim Parasitol 1963, 14:107-122.
42. Christensen HA, Herrer A, Telford SR Jr: Leishmania braziliensis s. lat. isolated from Lutzomyia panamensis in Panama. J Parasitol 1969, 55:1090-1091

43. Christensen HA, Herrer A: Attractiveness of sentinel animals to vectors of Leishmaniasis in Panama. Am J Trop Med Hyg 1973, 22:578-584.

44. Thatcher VE, Hertig M: Field studies on the feeding habitats and diurnal shelters of some Phlebotomus sandflies (Diptera: Pshychodidae) in Panama. Ann Entomol Soc Amer 1966, 59:46-52.

45. Rutledge LC, Ellenwood DA: Production of Phlebotomine sandflies on the open forest floor in Panama: Hydrologic and physiographic relations. Environ Entomol 1975, 4:78-82.

46. Herrer A, Christensen HA: Infrequency of gross lesions among Panamanian forest animals with Cutaneous Leishmaniasis. Parasitology 1975, 71:87-92.

47. Rutledge LC, Walton BC, Ellenwood DA: A transect study of sand fly populations in Panama (Diptera: Psychodidae). Envir Entomol 1976, 5(6):1149-1154.

48. Christensen HA, Herrer A, Telford SR: Enzootic Cutaneous Leishmaniasis in Eastern Panama II. Entomological investigations. Ann Trop Med Parasitol 1972, 66:55-66.

49. Hertig M, McConnell E: Experimental infection of Panamanian Phlebotomus sandflies with Leishmania. Exp Parasit 1963, 14:92-106.

50. Fairchild GB, Hertig M: Notes on the Phlebotomus of Panama I. The subgenus Brumptomyia Franca and Parrot 1921. Ann Entomol Soc Amer 1947, 40:610-616.

51. Fairchild GB, Hertig M: Notes on the Phlebotomus of Panama (Diptera: Psychodidae) II. Description of three new species. Ann Entomol Soc Amer 1947, 40:617-623.

52. Fairchild GB, Hertig M: Notes on the Phlebotomous of Panama (Diptera: Psychodidae) III. Phlebotomus cruciatus Coq. trinidadensis Newst and gomezi Nitz. Ann Entomol Soc Amer 1948, 41:247-257.

53. Fairchild GB, Hertig M: Notes on the Phlebotomus of Panama (Diptera: Psychodidae) IV. Phlebotomus atroclavatus, P. chiapannensis Damp and some related forms from the West Indies and Mexico. Ann Entomol Soc Amer 1948, 41:455-467.

54. Fairchild GB, Hertig M: Notes on the Phlebotomus of Panama (Diptera: Psychodidae) VI. Phlebotomus shannon Dyar and related species. Ann Entomol Soc Amer 1950, 43:523-533.

55. Fairchild GB, Hertig M: Notes on the Phlebotomus of Panama (Diptera: Psychodidae) VII. The subgenus Shannoniana Pratt. Ann Entomol Soc Amer 1950, 44:399-422.

56. Fairchild GB, Hertig M: Notes on the Phlebotomus of Panama IX. Descriptions of seven new species. Ann Entomol Soc Amer 1952, 45(4):505-528.

57. Fairchild GB, Hertig M: Notes on the Phlebotomus of Panama (Diptera: Psychodidae) X. Phlebotomus aragoai, P. barrettoi and two new species. Ann Entomol Soc Amer 1953, 46:21-34.

58. Fairchild GB, Hertig M: Notes on the Phlebotomus of Panama (Diptera: Psychodidae) XI. The male of $P$. cruciatus Coq., and notes on related species. Ann Entomol Soc Amer 1953, 46:373-385.

59. Fairchild GB, Hertig M: Notes on the Phlebotomus of Panama (Diptera: Psychodidae) XII. The group Anthophorus, with descriptions of four new species from Panama and Mexico. Ann Entomol Soc Amer 1956, 49:307-312.

60. Fairchild GB, Hertig M: Notes on the Phlebotomus of Panama XIII. The Vexator group, with descriptions of new species from Panama and California. Ann Entomol Soc Amer 1957, 50:325-334.

61. Fairchild GB, Hertig M: Notes on the Phlebotomus of Panama (Diptera: Psychodidae) XIV. Phlebotomus vespertilionis and related species. Ann Entomol Soc Amer 1958, 51:509-516.

62. Fairchild GB, Hertig M: Notes on the Phlebotomus of Panama (Diptera: Psychodidae) XV. Four apparently new synonymies. Proc Entomol Soc Wash 1958, 51:203-205.

63. Fairchild GB, Hertig M: Notes on the Phlebotomus of Panama (Diptera: Psychodidae) XVI. Descriptions of new and little-known species from Panama and Central America. Ann Entomol Soc Amer 1961, 52:121-124.

64. Christensen HA, Fairchild GB: Lutzomyia tintinabula n. sp. (Diptera: Psychodidae) from Panama. J Med Entomol 1971, 8:301-303.

65. Fairchild GB, Hertig M: Notes on the Phlebotomus of Panama (Diptera: Psychodidae) VIII. Two new species of Warileya. Ann Entomol Soc Amer 1951, 44:424-429. 
66. Tesh RB, Chaniotis BN, Aronson MD, Johnson KM: Natural host preference of Panamanian Phlebotominae sand flies as determined by precipitin test. Am J Trop Med Hyg 1971, 20(1):150-156.

67. Tesh RB, Chaniotis BN, Carrera BR, Johnson KM: Further studies on the natural host preferences of Panamanian Phlebotominae sand flies. Am J Epidemiol 1972, 95:88-93.

68. Christensen HA, Vasquez AM: The tree-buttress biotope: a pathobiocenose of Leishmania braziliensis. Am J Trop Med Hyg 1982, 31(2):243-251.

69. Fairchild GB, Theodor O: On Lutzomyia flaviscutellata (Mangabeira) and Lutzomyia olmeca (Vargas and Díaz-Najera). J Med Entomol 1971, 8:153-159.

70. Christensen HA: Check list of the Phlebotomine sandflies (Diptera: Psychodidae) of Panama including two species not previously reported. Mosq News 1972, 32:88-89.

71. Chaniotis BN: Use of external characters for rapid identification of Phlebotomine sandflies in vector studies. J Med Entomol 1974, 11:501.

72. Hertig M, Fairchild GB: Notes on the Phlebotomus of Panama (Diptera: Psychodidae) V. The second sternite as a taxonomic character. Proc Ent Soc Wash 1950, 52:91-95.

73. Hanson WJ: The breeding places of Phlebotomus in Panama (Diptera: Psychodidae). Ann Ent Soc Amer 1961, 54:317-322

74. Hanson WJ: The immature stages of the sub-family Phlebotominae in Panama (Diptera: Psychodidae). Ph.D. thesis 1968. University of Kansas. University Microfilms Inc. Ann. Arbor. Michigan.

75. Valderrama A, Tavares MG, Andrade Filho JD: Phylogeography of Lutzomyia gomezi (Diptera: Phlebotominae) on the Panama Isthmus. Parasit Vectors 2014, 7:9.

76. Rutledge $\mathrm{CL}$, Ellenwood DA: Production of Phlebotomine sand flies on the open forest floor in Panama: the species complement. Environ Entomol 1975, 4:71-77

77. Rutledge LC, Ellenwood DA: Production of Phlebotomine sand flies on the open forest floor in Panama: phytologic and edaphic relations. Environ Entomol 1975, 4:83-89.

78. Johnson PT, Hertig M: The rearing of Phlebotomus sand flies (Diptera: Psychodidae) II. Development and behavior of Panamanian sand flies in laboratory culture. Ann Entomol Soc Amer 1961, 54:764-776.

79. Rutledge LC, Mosser HL: Biology of immature sand flies at the bases of trees in Panama. Environ Entomol 1972, 1:300-309.

80. Chaniotis BN, Correa MA, Tesh RB, Johnson KM: Daily and seasonal man biting activity of Phlebotominae sand flies in Panama. J Med Entomol 1971, 8:415-420.

81. Chaniotis BN, Correa MA, Tesh RB, Johnson KM: Diurnal resting sites of Phlebotominae sand flies in Panamanian tropical forest. J Med Entomol 1972, 9:91-98.

82. Thatcher VE, Hertig M: Field studies on the feeding habits and diurnal shelters of some Phlebotomus sandflies (Diptera: Psychodidae) in Panama. Ann Ent Soc Amer 1966, 59:46-52.

83. Chaniotis BN, Correa MA: Comparative flying and biting activity of Panamanian Phlebotomine sandflies in mature forest and adjacent open space. J Med Entomol 1974, 11:115-116.

84. Chaniotis BN, Correa MA, Tesh RB, Johnson KM: Horizontal and vertical movements of Phlebotominae sand flies in a Panamanian rain forest. $J$ Med Entomol 1974, 11:369-375.

85. Chaniotis BN: Improved trapping of Phlebotomine sand flies (Diptera: Psychodidae) in light traps supplemented with dry ice in a Neotropical rain forest. J Med Entomol 1983, 20(2):222-223.

86. Chaniotis BN, Neely JM, Correa MA, Tesh RB, Johnson KM: Natural population dynamics of Phlebotominae sand flies in Panama. J Med Entomol 1971, 8:339-352.

87. Christensen HA, Herrer A: Panamanian Lutzomyia (Diptera: Psychodidae) host attraction profiles. J Med Entomol 1980, 17:522-528.

88. Rutledge $L G$, Ellenwood DA, Johnston $L$ : An analysis of sand fly light trap collections in the Panama Canal Zone (Diptera: Psychodidae). $J$ Med Entomol 1975, 12:179-183.

89. Thatcher VE: Studies of Phlebotomone sandflies using castor oil traps baited Panamanian animals. J Med Entomol 1968, 5(3):293-297.
90. Comer JA, Tesh RB: Phlebotomine sand flies as vectors of vesiculoviruses: a review. Parasitology 1991, 55(1):143-150.

91. Schreck CE, Kline DL, Chaniotis BN, Wilkinson N, McGovern TP, Weidhaas DE: Evaluation of personal protection methods against Phlebotomine sand flies including vectors of Leishmaniasis in Panama. Am J Trop Med Hyg 1982, 31(5):1046-1053.

doi:10.1186/1756-3305-7-218

Cite this article as: Dutari and Loaiza: American Cutaneous

Leishmaniasis in Panama: a historical review of entomological studies on anthropophilic Lutzomyia sand fly species. Parasites \& Vectors

2014 7:218

\section{Submit your next manuscript to BioMed Central and take full advantage of:}

- Convenient online submission

- Thorough peer review

- No space constraints or color figure charges

- Immediate publication on acceptance

- Inclusion in PubMed, CAS, Scopus and Google Scholar

- Research which is freely available for redistribution 